DOI 10.18551/rjoas.2020-07.12

\title{
DEVELOPING COUNTRIES ECONOMIC GROWTH, CAUSALITY AND CONVERGENCE: RWANDA AND PERU
}

\author{
Niyigaba Jean* \\ School of Economics, Huazhong University of Science and Technology, Wuhan, China \& \\ School of Economics, University of Rwanda, Kigali, Rwanda \\ Peng Daiyan \\ School of Economics, Huazhong University of Science and Technology, Wuhan, China \\ *E-mail: niyigav@yahoo.fr
}

\begin{abstract}
Economic growth and convergence issues arise in humanity continually, especially in developing countries. With Rwandan and Peruvian common vital economic variables from 1960 to 2017, we analyze their economic growth, causality, and convergence. The cointegration shows the long-run equilibrium correlation among the explained and explanatory variables, indicating the causality occurrence. The causality direction is defined by the Error Correction Model (ECM) using the Chi-square (X2) short-run test, long-run Ttest, and joint F-test statistics. The estimated values support a generalized Broadwell model equation with linear and quadratic terms. Through ANOVA with the $F$ test, the economic convergence scenario for the two countries is testified. Thus, joint countries' strategies for economic improvement are suggested with the reduction of unnecessary losses.
\end{abstract}

\section{KEY WORDS}

Cointegration, causality, convergence, generalized Broadwell model equation with linear and quadratic terms.

Throughout recent decades the world has remained described by the interdependence growing of national economies and the global scope of markets, delivery systems, capital, labor, and technology. Globalization trend is manifested in maintaining the growth of the Global Business, investment flows, technologies, as well as in the convergence of national economies and social practices. In most countries, this integration trend led to the quick increment in per capita incomes, while developing nations stagnated at per capita income levels reached since the earlier decades.

The neoclassical ideal assumes that economies converge to their steady-state, and the convergence speed linked conversely to the gap within the adequate income and its corresponding steady-state, Solow (2009).

For the absolute convergence, economies thought to hold the identical steady-state where the variation within nations is in their capital level initially and considering this idea, developing countries will rise faster than the developed ones as they are much away from the steady-state.

On the other hand, countries with related fundamental characteristics, including favorites, technologies, population growth rates, and policies, converge mutually in the longrun despite their original states. This proposition identified as conditional convergence and is the basis of this research on convergence ideas. Peru and Rwanda are two emerging independent nations; Latino American and African coastal and landlocked, respectively. Despite the geographic location areas, the two countries have had a similarity on some key variables contributing to their economic development. Here comes also the idea of relating their economic growth and convergence in this paper.

Rwanda economic development. A Central East African landlocked country covering 26,338 square kilometers, and a population of 12.158 million; More than two decades after genocide devastated the country, Rwanda continues to implement its economic growth 
reform programs but still struggling with a chronic trade deficit of $\$ 169.91$ Million as in 2018 . Its top import origin is China, with \$551.85 Million in 2018 NISR (2018).

Peru economic development. In South America that is home to a section of the Amazon rainforest, Peru is a country in western of this area, with $1,285,216 \mathrm{~km} 2$ and $32,162,184$ of Populations. According to the Peruvian Bureau of Statistics of (Instituto Nacional de Estadistica e Informatica (INEI), two attenuating factors are leading the GDP external shock though at a slower speed. The first was the reasonable financial policy control on monetary and exchange policies allowing the country to decline in fiscal income out spending drastically and allowing the country to foreign stocks for an ordered arrangement of the exchange rate. Secondary the mining production realized projects in the boom years raising the exports counteracting the internal demand weakness. With these circumstances, Peruvian current account deficit decreased swiftly, from 4.8 to 1.1 percent of GDP from 2015 to 2017 while foreign reserves prevailed stable at 27 percent of GDP INEI (2019).

Growth and convergence empirics. Convergence hypothesis experienced various confirmations in the literature, several stylized empirical shreds of evidence concerning it. Following Maputo's analysis using the modified log-linear growth model, the Zimbabwean economy is driven by agriculture as it presents a stronger positive correlation with economic growth, Alexander Mapfumo (2012).

Based on panel data, Latif Dramani's study tested the convergence of the Monetary Union and Economic of the West African (UEMOA) and the Monetary and Economic Community of Central Africa (CEMAC) zones. Findings reveal that the convergence process and the integration have not been carried out consistently in the Franc Zone: the method provided a higher accent in UEMOA than in CEMAC Zone. Further, the procedure used to estimate the conditional convergence model made it possible to highlight the existence of critical variables that help to maximize the convergence speed, Dramani (2010).

Concerning the 52 African nations with data for the period 1980-2011, besides a few of them, other results provide inadequate confirmation of $\beta$-convergence, $\sigma$-convergence, and conditional $\beta$-convergence among Africa nations. In this research, Mustapha proposed a breakdown structure of the Generalized Gini coefficient to analyze the inequality changes over time concerning the component progressivity and income distribution with component re-ranked. Using this technics, the inequality examination trends within African nations assume a no convergence of any kind that over time, directing to the inequality increase situation. Several results indicate the tendency to lower economic growth rates versus the massive rise of population growth rates in African nations, Djennas and Ferouani (2014).

In the same areas, with the augmented Solow model, including both GDP per worker and the per capita GDP, Khan measured the convergence using the dynamic system generalized methods of moments (GMM) with panel data. According to the results on conditional $\beta$-convergence he demonstrated that African nations Per capita GDP rates of convergence are weaker than the ones of GDP per worker, Khan (2014).

\section{METHODS OF RESEARCH}

The cointegration test between variables used to decide on the correlation and the Analysis of variance (ANOVA) for convergence scenario. We are using the per capita variables at a given time to avoid the currency depreciation effects, and all values are in USD with 2010 as the base year.

Table 1 - Research explained and explanatory variables

\begin{tabular}{ll}
\hline Explained variables (Constant base year 2010 in USD) & Per capita GDP (GDPc) \\
\hline \multirow{2}{*}{ Explanatory variables (Constant base year 2010 in USD) } & Per capita Gross capital formation (GCFc) \\
& Per capita Agriculture, forestry, and fishing, value added (Agrc) \\
& Per capita International tourism, expenditures (IntTc) \\
& Per capita Industry (including construction), value added (Indc) \\
& Per capita Manufacturing, value added (Manc) \\
\hline
\end{tabular}

Based on the generalized Broadwell model equation with linear and quadratic terms Yamazaki (2000), Broadwell (1964), following also our time series data status. Following also 
the time series data status. It is credible to determine the variables long run and short-run correlation as follows:

$$
\text { LGDPc }=\alpha_{0}+\alpha_{1} \text { LGCFc }+\alpha_{2} \text { LAgrc }+\alpha_{3} \text { LAgrc }^{2}+\alpha_{4} \text { LIntTc }+\alpha_{5} \text { LIndc }+\alpha_{6} \text { LManc }+u_{i}
$$

$\alpha_{2}$ sign is presumed to be negative, while positive signs are exacted for $\alpha_{1}, \alpha_{3}, \alpha_{4}, \alpha_{5}$ and $\alpha_{6}$. If discovers that the sign for $\operatorname{LAgrc}^{2}$ is insignificant statistically, it shows a monotonic relationship between the GDPc and Agrc. With the optimization rules Bony (2018) on LAgrc and $\operatorname{LAgrc}^{\wedge} 2$, the turning point occurs at an agriculture output level equal to $\alpha_{1} / 2 \alpha_{2}$ (in logarithms) as from the equation (1), $\frac{\text { LLGDPc }}{\text { DLAgrc }}=0$ iff LAgr $=\alpha_{1} / 2 \alpha_{2}$ That means, at the starting point, agriculture production decreased while the country's economy increased. However, the increasing together started as agriculture production passed this turning point. This scenario is described by the fact that at the starting point, for boosting other economic areas, a part of effort was shifting from the agriculture sector to other areas thereafter at the turning point the remained efforts in the sector restored the situation. The error term ui, is considered to be distributed normally with zero mean and constant variance, $\alpha_{0}$ is Intercept while $\alpha 1, \alpha_{2}, \alpha_{3}, \alpha_{4}, \alpha_{5}$ and $\alpha_{5}$ are Slopes of the explanatory variables. For the avoidance of both overestimating and counterfeit regression result of the explanatory variables, the linear models nested, with their R-square $\left(R^{2}\right), R^{2}$-adjusted, and Jarque Bera (JB) tests statistics Jarque (1980) are applied to determine how strong the LGCFc, LAgrc, LIntTc, LIndc, and LManc react collectively on the LGDPc variable efficiency description as follows:

$$
\begin{aligned}
& \text { LGDPc }=a_{0}+a_{1} \text { LGCFC }+\alpha_{2} \text { LAgrc }+\alpha_{4} \text { LIntTc }+\alpha_{5} \text { LIndc }+\alpha_{6} \text { LManc }+u_{i} \\
& \text { LGDPc }=a_{0}+a_{1} \text { LGCFC }+a_{2} \text { LAgrc }+\alpha_{3} \text { LAgrc }^{2}+\alpha_{4} \text { LIntTc }+\alpha_{5} \text { LInd }+\alpha_{6} \text { LManc }+u_{i}
\end{aligned}
$$

If adding LAgrc ${ }^{2}$ result on an adjusted $R^{2}$ that is insignificantly even at 1 percent, we strength conclude that the inclusion of $\mathrm{LAgrc}^{2}$ in the model is not useful, indicating a monotonic correlation between the GDPc and Agrc.

Analysis examines the long-run and or short-run correlation among the variables and use the error-correction model $(E C M)$ to captures the short-run dynamics of the variables. Three tests of no stationarity (unit root), including the Augmented Dickey Fuller(ADF) Dickey David A. and Fuller Wayne A (1981), Phillips Perron (PP) Phillips (1988), and Kwiatkowski Phillips Schmidt Shin (KPSS) Kwiatkowski and Phillips (1992) Are applied to examine the unit root presence and variables integration order. Secondary, for series with identical order of integration, the Johansen method is used for variables cointegration test Søren Johansen (1990). If the cointegration appeared, need to progress with Vector Error Correction Model (VCEM) as the typical OLS method used to estimate an equation doesn't reach to the deceptive regression outcome Denisard C.O. Alves (2003). If no cointegration, only the VAR model with the OLS is applied.

The cointegration occurrence symbolizes the variable's long-run equilibrium correlation. For correcting the disequilibrium appeared in the regression process, the use of error correction model (ECM) is credible, and the error-correction term (ECT) causality tests are specified as follows:

$$
\begin{aligned}
& \Delta \mathrm{LY}_{t}=\beta_{10}+\sum_{i=1}^{k-1} \beta_{11 i} \Delta \mathrm{LY}_{t-i}+\sum_{i=1}^{k-1} \beta_{12 i} \Delta \mathrm{LX}_{t-i}+\lambda_{1} \mathrm{ECT}_{t-1}+\varepsilon_{1 t} \\
& \Delta \mathrm{LX}_{t}=\beta_{20}+\sum_{i=1}^{k-1} \beta_{21 i} \Delta \mathrm{LX}_{t-i}+\sum_{i=1}^{k-1} \beta_{22 i} \Delta \mathrm{LY}_{t-i}+\lambda_{2} \mathrm{ECT}_{t-1}+\varepsilon_{2 t}
\end{aligned}
$$

Where: $Y$ and $X$ represent the explained and explanatory variables respectively, and $\Delta$ sign is the first differentiation indicator. Based on Akaike's information criteria (AIC), it's feasible to define the most suitable (optimum) lag length $k$, with $k-1$ is the most suitable lag length reduced by one, and $\varepsilon_{\text {it }}$ are the serial error terms. $\beta_{111}, \beta_{12 i}, \beta_{21 i}, \beta_{22 i}$ are short-run changing 
(dynamic) coefficients of the model adjusting the long-run stability. The short-run causality runs from explanatory to explained variables, if the F-statistics and regressors statistical significance reject the joint null hypothesis of $\beta_{12 i}=0$. Error correction t-statistical term examines the long-run causal significance, and F- test statistics measure the strong causal effect. $\lambda i$ with a negative sign is the adjustment speed of parameter.

The error correction term $\left(E C T_{t-1}\right)$ is the residuals value lagged, received from the regression of the cointegration of the explained variable on the regressors.

$$
\mathrm{ECT}_{t-1}=\mathrm{LY}_{t-1}-b_{0}-b_{1} \mathrm{LX}_{t-1}
$$

In previous empirical literature there are different models applied for convergence test, but in this research we are following the theory and application of analysis of variance as defined by Brenton R. Clarke to test a hypothesis of equal means Clarke (2008). This done by grouping each variable with its correspondent in both countries, we can compare the means of Rwandan and Peruvian economic variables from 1960 to 2017 and decide if they are the same (converging) or not. It is performed by a comparison of countries per capita GDP means, and the explanatory variables mean one by one.

$$
F=\frac{M S T_{k}}{M S E}, M S T_{k}=\frac{J}{I-1} \sum_{i}^{n}\left(\mu_{i}-\mu_{. .}\right)^{2}, M S E=\frac{\sum_{i}^{n} S_{i}^{2}}{I}
$$

With: $M_{S T}$ : Mean Square of Treatment, MSE: Mean Square of Errors. $\mu_{i}$ : Individual treatment means, $\mu_{\text {.. }}$ : Grande mean, $\sum_{i}^{n} S_{i}^{2}$ : Sum of individual variance (for each treatment group), I: number of treatments.

\section{RESULTS OF STUDY}

From 1960 to 2017, at a constant base year 2010 in US\$, figures and summaries of both countries variables as below:

\begin{tabular}{|c|c|c|c|c|c|c|}
\hline Variables in USD & GDPC & AGRC & GCFC & INDC & INTTC & MANC \\
\hline Mean & 400.991 & 120.870 & 58.907 & 62.433 & 4.982 & 31.301 \\
\hline Std. Dev. & 124.407 & 31.444 & 56.274 & 23.380 & 6.782 & 7.129 \\
\hline Coefficient of variation CV (\%) & 31.025 & 26.015 & 95.530 & 37.448 & 136.131 & 22.777 \\
\hline Average growth rate intervals & GDPC in \% & AGRC in \% & GCFC in \% & INDC in \% & INTTC in $\%$ & MANC in \% \\
\hline ]1960-1970] & 0.130 & 1.664 & 0.349 & 45.002 & -2.085 & -2.030 \\
\hline ]1970-1980] & 2.102 & 10.795 & 2.790 & 9.591 & 2.876 & 2.686 \\
\hline ]1980-1990] & -1.407 & -0.575 & -2.987 & -53.768 & -1.326 & -1.007 \\
\hline ]1990-2000] & -0.957 & 2.907 & 2.549 & 54.140 & -3.110 & -5.224 \\
\hline ]2000-2010] & 5.433 & 9.873 & 2.844 & 9.878 & 6.558 & 5.361 \\
\hline ]2010-2017] & 4.374 & 8.619 & 2.849 & 11.426 & 6.077 & 3.808 \\
\hline General average growth rate & 1.467 & 5.332 & 1.290 & 13.168 & 1.309 & 0.472 \\
\hline
\end{tabular}

Table 2 - Summary statistics for Rwanda, 1960 to 2017

\begin{tabular}{|c|c|c|c|c|c|c|}
\hline Variables in USD & GDPC & AGRC & GCFC & INDC & INTTC & MANC \\
\hline Mean & 3738.383 & 268.376 & 639.744 & 1300.442 & 24.055 & 615.858 \\
\hline Std. Dev. & 911.695 & 52.683 & 337.878 & 316.407 & 22.884 & 115.779 \\
\hline Coefficient of variation CV (\%) & 24.387 & 19.630 & 52.815 & 24.331 & 95.132 & 18.800 \\
\hline Average growth rate intervals & GDPC in \% & AGRC in \% & GCFC in \% & INDC in \% & INTTC in \% & MANC in \% \\
\hline ]1960-1970] & 2.310 & 0.748 & 1.188 & 28.275 & 2.125 & 2.840 \\
\hline ]1970-1980] & 0.974 & 5.963 & -3.238 & 7.517 & 2.392 & 0.610 \\
\hline ]1980-1990] & -3.300 & -6.512 & -0.090 & 0.599 & -4.822 & -4.181 \\
\hline ]1990-2000] & 2.114 & 3.532 & 3.338 & 6.487 & 2.280 & 1.781 \\
\hline ]2000-2010] & 3.623 & 5.175 & 2.366 & 6.408 & 4.001 & 3.599 \\
\hline ]2010-2017] & 2.946 & 1.571 & 1.455 & 7.249 & 1.739 & 0.362 \\
\hline General average growth rate & 1.461 & 2.346 & 0.703 & 9.841 & 1.362 & 0.936 \\
\hline
\end{tabular}

Table 3 - Summary statistics for Peru 1960 to 2017 


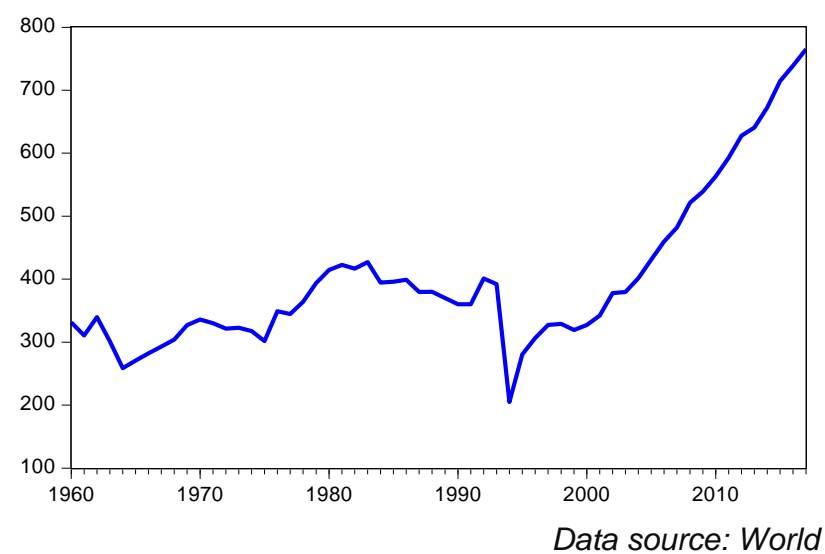

Figure 1 - Rwandan GDPc plot: 1960-2017 in USD

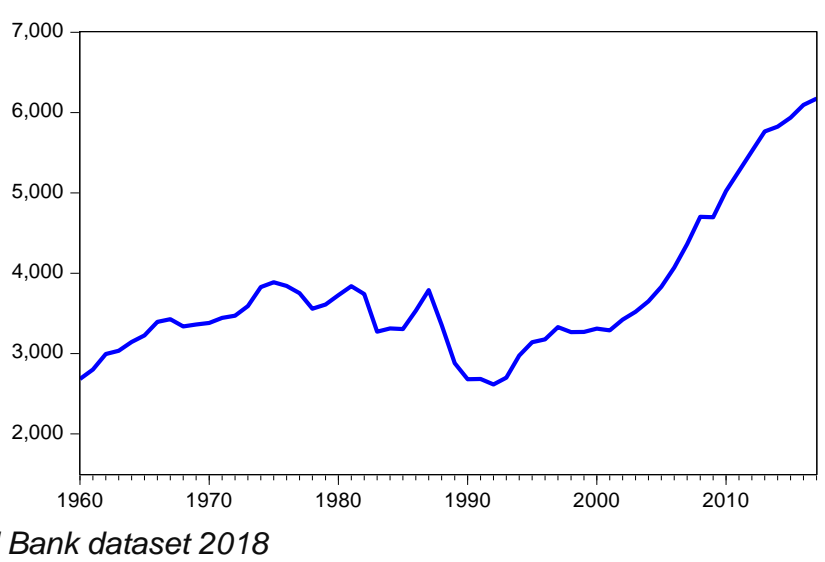

Figure 2 - Peruvian GDPc plot: 1960-2017 in USD

The test for collinearity in explanatory variables is done before the correlation analysis. If collinearity appeared, it has to be removed before. The variance Inflation factor (VIF) is used in this research to test for collinearity Gómez et al. (2016).

$$
\text { VIF of } j^{\text {th }} \text { independent variables }=\frac{1}{1-R_{j}^{2}}
$$

$\mathrm{R}_{\mathrm{j}}^{2}$ is the determination coefficient of $\mathrm{X} i$ on the rest of independent variables. If VIF $>10$, the collinearity is manifested.

Table 4 - Variance Inflation factor, with presence of collinearity

\begin{tabular}{|c|c|c|c|c|c|}
\hline \multicolumn{6}{|c|}{ vif(Multreg_Model) } \\
\hline Countries & GCFC & Agrc & IntTc & Indc & Manc \\
\hline Rwanda & 6.299084 & 6.242023 & 1.952104 & 18.258520 & 10.865315 \\
\hline Peru & 7.506135 & 2.522157 & 2.214496 & 11.651051 & 6.945637 \\
\hline
\end{tabular}

The Indc VIF on both countries is greater than 10; therefore, the collinearity is manifested, indicating the linear relationships between Indc and other independent variables. We ignorance that variable with VIF $>10$, as one of the ways to avoid it.

Table 5 - Variance Inflation factor, without multicollinearity

\begin{tabular}{lllll}
\hline & vif(Multreg_Model) & & & \\
\hline Countries & GCFc & Agrc & IntTC & Manc \\
Rwanda & 5.873608 & 5.404662 & 1.698085 & 1.380024 \\
Peru & 5.314428 & 2.477682 & 2.199937 & 4.101741 \\
\hline
\end{tabular}

After collinearity avoidance in the series our principal equations becomes:

$$
\begin{aligned}
& \text { LGDPc }=\alpha_{0}+\alpha_{1} \text { LGCFc }+\alpha_{2} \text { LAgrc }+\alpha_{4} \text { LIntTc }+\alpha_{5} \text { LManc }+u_{i} \\
& \text { LGDPc }=\alpha_{0}+\alpha_{1} \text { LGCFC }+\alpha_{2} \text { LAgrc }+\alpha_{3} \text { LAgrc }^{2}+\alpha_{4} \text { LIntTc }+\alpha_{5} \text { LManc }+u_{i}
\end{aligned}
$$

Unit root is approved by checking the time-series properties through: ADF, PP, and KPSS tests as in Table 6, and Table 7. Variables are not stationary at levels and stationary at first difference I (1), indicating the order one integration.

Economically, the interdependency of variables $Y$ and $X$ is rarely instantaneous; that means $Y$ responds to $X$ with a lapse of time; such lapse of time is described as lag. More extra lags cause the degrees freedom loss, which leads to statistically insignificant coefficients and can cause multicollinearity. In contrast, few lags could lead to misspecification errors. Choosing of the lag length is no hard-and-fast way; it is an 
experimental exercise, and in general, for annual data, the number of arbitrary lags is 1 to 2 , quarterly 1 to 8 and monthly data 6,12 , or 24 .

Table 6 - Rwandan variables unit roots tests results

\begin{tabular}{|c|c|c|c|c|c|c|}
\hline & \multicolumn{2}{|l|}{ ADF } & \multicolumn{2}{|l|}{$\mathrm{PP}$} & \multicolumn{2}{|l|}{ KPSS } \\
\hline & Level & 1st diff. & Level & 1st diff. & Level & 1st diff. \\
\hline LGDPC & -0.5436 no & $-8.9339^{\star \star \star}$ & -0.0478 no & $-9.2065^{\star \star \star}$ & $0.6454^{* \star}$ & $0.2681 \mathrm{no}$ \\
\hline LGCFC & -0.4337 no & $-10.8050^{* * *}$ & -0.9967 no & $-10.8050^{* * *}$ & $0.7638^{* * *}$ & 0.0983 no \\
\hline LAGRC & 0.0140 no & $-8.6039^{\star * *}$ & -0.6494 no & $-9.2167^{* * *}$ & $0.7097^{*}$ & 0.0650 no \\
\hline LAGRC^2 & 0.1909 no & $-8.5271^{* * *}$ & -0.4547 no & $-9.0120^{\star * *}$ & $0.7114^{\star \star}$ & 0.0968 no \\
\hline LINTTC & 0.0394 no & $-4.0299^{\star * \star}$ & -4.8586 no & $-24.7218^{\star \star \star}$ & $0.9175^{\star \star \star}$ & 0.1640 no \\
\hline LMANC & -1.6354 no & $-7.8115^{\star \star *}$ & -1.6913 no & $-7.8363^{\star \star *}$ & $0.11730^{*}$ & 0.1982 no \\
\hline
\end{tabular}

Table 7 - Peruvian variables unit roots tests results.

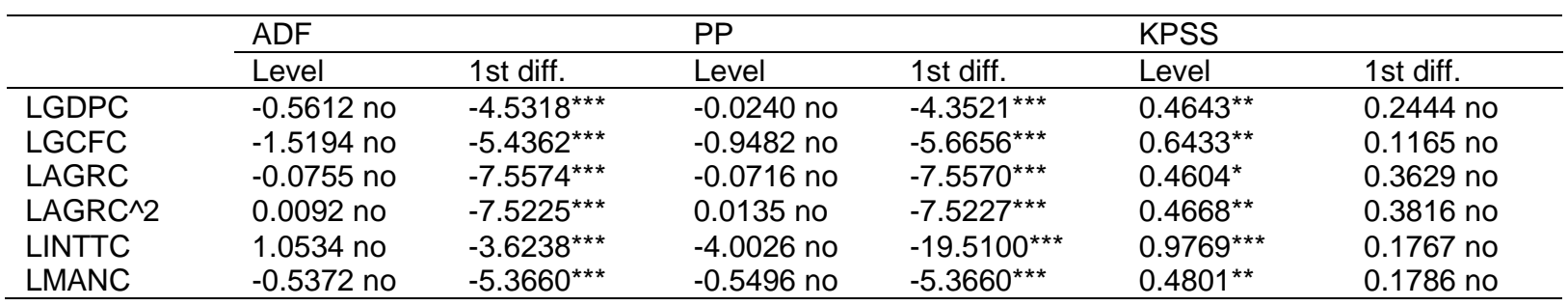

Note: The unit-roots except the KPSS are with a null hypothesis that the series has a unit root against the alternative of being stationary. The null of KPSS states that the variable is stationary. Individual intercepts are included in test regressions. *, **, ${ }^{* *}$ means that the null hypothesis of the unit root tests is rejected at a 10\%, 5\%, $1 \%$ level, and (no) indicate that the null hypothesis of the unit root test is not rejected.

An appropriate way to decide on this quagmire is to determine using different five lag selection criteria tested as in Table 8 and Table 9. With all those criteria, the most recommended in this research on both two countries, as, is the lag one. Implying that the GDPc responds to the mentioned independent variables with a lapse of time equal to one year.

Table 8 - Rwandan variables Lag length Criteria Table 9 - Peruvian variable Lag length Criteria

\begin{tabular}{lllllll}
\hline Lag & LogL & LR & FPE & AIC & SC & HQ \\
\hline 0 & 40.9 & NA & $1.16 e-08$ & -1.2 & -1.0 & -1.2 \\
1 & 241.7 & 351.4 & $3.25 e-11^{*}$ & $--7.1^{*}$ & $-5.6^{*}$ & $-6.54^{*}$ \\
2 & 275.1 & $51.4^{*}$ & $3.72 \mathrm{e}-11$ & -7.03 & -4.2 & -5.94 \\
\hline
\end{tabular}

\begin{tabular}{lllllll}
\hline Lag & LogL & LR & FPE & AIC & SC & HQ \\
\hline 0 & 218.2 & NA & $2.06 \mathrm{e}-11$ & -7.6 & -7.4 & -7.5 \\
1 & 506.9 & $505.2^{*}$ & $2.50 \mathrm{e}-15^{\star}$ & $-16.6^{*}$ & $15.1^{*}$ & $16.02^{*}$ \\
2 & 539.0 & 49.2 & $3.00 \mathrm{e}-15$ & -16.5 & -13.6 & -15.4 \\
\hline
\end{tabular}

Note: * indicates lag order selected by the criterion LR: sequential modified LR test statistic, FPE: Final prediction error, AIC: Akaike information criterion, SC: Schwarz information criterion, HQ: Hannan-Quinn information criterion. (Each test at $5 \%$ level).

The following step is to test whether the variables for Peru and Rwanda in Equation (9) or (10) are cointegrated, are cointegrated. However, first, we need to precise the appropriate Equation between (9) and (10) as in Table 10.

The results indicate Equation (10) as the appropriated; therefore, the Johansen test is basing on the indicated Equation. At a 0.05 significance level, both trace and eigenvalue cointegration tests reject the null hypothesis of no cointegrated equation. They designate at least one cointegration equation with lag one. Hence, there is a long-run correlation between Rwandan and Peruvian dependent and independents variables as described their normalized cointegrating Equations variables in Table 12.

The coefficients of Equation (10) shown in Table 11 indicate how the correlation between income and agriculture is: at the starting point, agriculture production decreased at the same time, the country's economy increased, but at a certain point in time, the increasing together started. Thus it relates a U-shape and supporting the quadratic form hypothesis. The U-shape turning point occurs at the time with agriculture output (in logarithm) of 4.6 and of 5.3, which are nearest the year 1974 for Rwanda and 1984 for Peru, respectively, 
according to the agriculture time series period 1960-2018. The R2, adjusted R2, and JBstatistic values manifested in Table 11 show that Equation (10) is suitable as, Summing LAGRc $^{2}$ reflect in significant adjusted $R^{2}$ greater than $0.001(>0.001)$, and the $p$ value of the Jarque Bera tests for Equation (10) is smaller than the one for Equation (10). All those situations in both countries indicate that Equation (10) is the appropriated to express the correlation among variables.

Table 10 - Coefficients of Equations (9) and (10) for LGDPc

\begin{tabular}{|c|c|c|c|c|c|}
\hline & & Equation (9) for Rwanda & Equation (10) for Rwanda & Equation (9) for Peru & Equation (10) for Peru \\
\hline \multirow{6}{*}{ 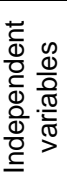 } & LGCFC & 0.802687 & 0.195768 & 0.118744 & 0.055079 \\
\hline & LAGRC & -4.589419 & -12.81051 & -0.258870 & -5.261338 \\
\hline & LAGRC^2 & & 1.381892 & & 0.453274 \\
\hline & LINTTC & 0.460579 & -0.047576 & 0.085926 & 0.081758 \\
\hline & LMANC & 084837 & 0.117314 & 1.048253 & 1.064086 \\
\hline & Constant (c) & 20.82904 & 34.43879 & 1.942383 & 16.04191 \\
\hline \multirow{4}{*}{ 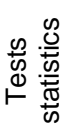 } & $\mathrm{R}^{2}$ & 0.944629 & 0.964133 & 0.957178 & 0.972062 \\
\hline & $\operatorname{Adj}-R^{2}$ & 0.940450 & 0.960685 & 0.953946 & 0.969375 \\
\hline & $\mathrm{JB}$ & 3.05537 & 0.4763556 & 9.615225 & 0.605261 \\
\hline & p val. & 0.217031 & 0.788061 & 0.008167 & 0.738872 \\
\hline
\end{tabular}

Table 11 - Variables cointegration texts

\begin{tabular}{|c|c|c|c|c|c|c|}
\hline Country & Test & Hypothesized No. of CE(s) & Eigenvalue & Statistic & 0.05 Critical Value & Prob. ${ }^{* *}$ \\
\hline \multirow[t]{4}{*}{ Rwanda } & Trace & None * & 0.536015 & 107.9386 & 95.75366 & 0.0056 \\
\hline & & At most 1 & 0.430033 & 64.93609 & 69.81889 & 0.1153 \\
\hline & Max-eigenvalue & None * & 0.536015 & 43.00252 & 40.07757 & 0.0227 \\
\hline & & At most 1 & 0.430033 & 31.48191 & 33.87687 & 0.0940 \\
\hline \multirow[t]{6}{*}{ Peru } & Trace & None * & 0.617361 & 132.5159 & 95.75366 & 0.0000 \\
\hline & & At most 1 * & 0.499236 & 78.71877 & 69.81889 & 0.0082 \\
\hline & & At most 2 & 0.205155 & 39.98806 & 47.85613 & 0.2229 \\
\hline & Max-eigenvalue & None * & 0.617361 & 53.79709 & 40.07757 & 0.0008 \\
\hline & & At most 1 * & 0.499236 & 38.73071 & 33.87687 & 0.0122 \\
\hline & & At most 2 & 0.205155 & 12.85803 & 27.58434 & 0.8926 \\
\hline
\end{tabular}

Note: Trace and Max-eigenvalue tests indicate 1 and 2 cointegrated eqn(s) for Rwandan and Peruvian respectively at the 0.05 level. * denotes rejection of the hypothesis at the 0.05 level, ${ }^{* *}$ MacKinnon-Haug-Michelis (1999) p-values.

Table 12 - Normalized cointegrating coefficients (standard error in parentheses)

\begin{tabular}{|c|c|c|c|c|c|c|c|}
\hline & LGDPC & LGCFC & LAGRC & LAGRC_2 & LINTTC & LMANC & Intercept \\
\hline & 1.000000 & & 12.811 & -1.382 & 0.048 & -0.117 & -34.439 \\
\hline 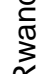 & & $(0.03235)$ & $(1.85863)$ & $(0.19798)$ & $(0.01051)$ & $(0.05219)$ & \\
\hline$\frac{0}{0}$ & 1.000000 & $\begin{array}{l}-0.055 \\
(0.05665)\end{array}$ & $\begin{array}{l}5.261 \\
(3.07210)\end{array}$ & $\begin{array}{l}-0.453 \\
(0.27585)\end{array}$ & $\begin{array}{l}-0.082 \\
(0.01185)\end{array}$ & $\begin{array}{l}-1.064 \\
(0.09592)\end{array}$ & -16.042 \\
\hline
\end{tabular}

Note: The LGDPC as the dependent variable and the signs of confidents are reversed in the long-run. Thus, except the LINTTC in Rwanda, all others Rwandan and Peruvian chosen independent variables have positive impact on the LGDPC in the long-run.

The cointegration indicates causality existence in one direction, at least though, it does not designate the causal relationship direction Oxley and Greasley (1998), Engle et al. (1987). The ECM acquired from the long-run cointegrated vectors and conducted based on causality tests is used for causality direction light shedding as in the following Table 13 and Table 14.

Analysis of variance (ANOVA), with $F$ test distribution calculated in Equation (7), compares the means of variables for two countries on the whole period, identifying the convergence status. Table 15 shows how the comparison was made, grouping all variables of the two countries together accordingly, comparing the explained and explanatory variables mean one by one from 1960 to 2017 . 
Table 13 Rwandan causality tests results

\begin{tabular}{|c|c|c|c|c|c|c|c|c|}
\hline & & $\Delta \mathrm{LGDPC}$ & $\triangle \mathrm{LGCFC}$ & $\Delta \mathrm{LAGRC}$ & $\Delta$ LAGRC 2 & $\Delta$ LINTTC & $\Delta$ LMANC & All \\
\hline \multirow{6}{*}{ 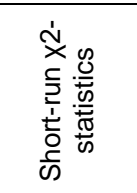 } & $\triangle \mathrm{LGDPC}$ & & $2.730^{*}$ & 0.199 & 0.254 & $6.436^{\star *}$ & 1.120 & $12.081^{* *}$ \\
\hline & $\triangle \mathrm{LGCFC}$ & 2.334 & & 2.447 & 2.746 & 0.073 & 1.446 & 7.745 \\
\hline & $\triangle \mathrm{LAGRC}$ & $3.300^{*}$ & $2.930^{*}$ & & 0.797 & $8.863^{\star * *}$ & 0.132 & $9.932^{*}$ \\
\hline & $\Delta$ LAGRC_2 & $3.322^{*}$ & $2.815^{\star}$ & 0.839 & & $8.750^{* *}$ & 0.161 & $9.809^{*}$ \\
\hline & $\Delta$ LINTTC & 1.025 & 0.378 & $3.359^{*}$ & $3.250^{*}$ & & 2.694 & 7.349 \\
\hline & $\triangle$ LMANC & 0.232 & 0.107 & $2.797^{*}$ & $3.112^{*}$ & 1.942 & & $11.514^{\star *}$ \\
\hline $\begin{array}{l}\text { Long-run } \\
\text { t-statistics }\end{array}$ & ECT & $-2.936^{\star *}$ & -0.319 & $-4.480^{\star \star *}$ & $3^{* * *}$ & -1.410 & $-1.728^{*}$ & \\
\hline \multirow{6}{*}{ 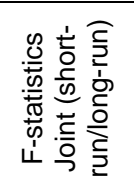 } & $\Delta \mathrm{LGDPC/ECT}$ & & 1.426 & $6.718^{\star *}$ & $7.885^{\star \star \star}$ & 1.954 & 2.773 & \\
\hline & $\Delta \mathrm{LGCFC/ECT}$ & 0.083 & & $7.926^{\star * *}$ & $8.811^{* * *}$ & 0.341 & 1.477 & \\
\hline & $\triangle \mathrm{LAGRC/ECT}$ & 0.036 & 2.710 & & $11.702^{\star * *}$ & 1.750 & $3.044^{*}$ & \\
\hline & $\triangle \mathrm{LAGRC} 2 / \mathrm{ECT}$ & 0.150 & 2.169 & $11.416^{\star \star *}$ & & 1.639 & $3.321^{*}$ & \\
\hline & $\Delta$ LINTTC̄/ECT & $7.008^{* *}$ & $6.566^{\star *}$ & $11.487^{\star \star *}$ & $12.074^{\star * *}$ & & 0.038 & \\
\hline & $\triangle \mathrm{LMANC/ECT}$ & 1.46906 & 1.090 & $4.461^{\star *}$ & $4.656^{\star *}$ & 1.673 & & \\
\hline
\end{tabular}

Table 14 - Peruvian causality tests results

\begin{tabular}{|c|c|c|c|c|c|c|c|c|}
\hline \multirow{7}{*}{ 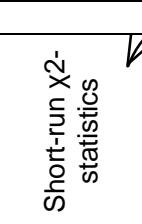 } & - & $\triangle \mathrm{LGDPC}$ & $\triangle \mathrm{LGCFC}$ & $\triangle \mathrm{LAGRC}$ & $\Delta$ LAGRC 2 & $\triangle$ LINTTC & $\triangle$ LMANC & All \\
\hline & $\Delta \mathrm{LGDPC}$ & & 0.003 & 0.964 & 0.834 & 0.828 & 0.509 & 6.708 \\
\hline & $\triangle \mathrm{LGCFC}$ & 0.258 & & 0.0350 & 0.061 & 2.463 & 0.038 & 5.607 \\
\hline & $\triangle \mathrm{LAGRC}$ & $7.435^{\star \star *}$ & 1.031 & & 1.025 & 0.199 & $4.677^{\star *}$ & $12.261^{* *}$ \\
\hline & $\Delta$ LAGRC_2 & $7.393^{* * *}$ & 1.056 & 1.074 & & 0.202 & $4.657^{\star \star}$ & $12.255^{\star \star}$ \\
\hline & $\Delta$ LINTTC & 0.206 & $10.138^{\star \star *}$ & 0.649 & 0.651 & & 0.010 & $19.896^{\star * *}$ \\
\hline & $\triangle$ LMANC & $3.569^{*}$ & 0.001 & 0.229 & 0.174 & $2.990^{*}$ & & 9.085 \\
\hline $\begin{array}{l}\text { Long-run } \\
\text { t-statistics }\end{array}$ & ECT & $1.823^{*}$ & 1.044 & $2.494^{\star *}$ & $2.485^{\star \star}$ & $4.532^{\star \star \star}$ & $2.469^{* *}$ & \\
\hline \multirow{6}{*}{ 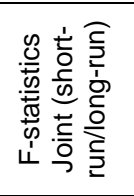 } & $\Delta \mathrm{LGDPC/ECT}$ & & 0.013 & $6.990^{* *}$ & $7.234^{* * \star}$ & 0.578 & 0.852 & \\
\hline & $\Delta \mathrm{LGCFC/ECT}$ & 1.946 & & 2.465 & 2.572 & 1.548 & 1.040 & \\
\hline & $\triangle \mathrm{LAGRC/ECT}$ & 0.024 & 0.145 & & 1.829 & 0.320 & 1.587 & \\
\hline & $\triangle \mathrm{LAGRC \_ 2/ECT}$ & 0.034 & 0.138 & 1.726 & & 0.321 & 1.669 & \\
\hline & $\triangle \mathrm{LINTTC/ECT}$ & $4.318^{\star *}$ & $5.460^{\star *}$ & $10.103^{\star * \star}$ & $10.179^{\star * *}$ & & 2.100 & \\
\hline & $\triangle \mathrm{LMANC/ECT}$ & 0.586 & 0.339 & $5.361^{* *}$ & $5.406^{\star *}$ & 0.193 & & \\
\hline
\end{tabular}

Note: The $x^{2}$-statistics test is with a null hypothesis that there is no short-run causality, the t-statistics test null hypothesis that there is no long-run causality and the $F$ test statistics null hypothesis there is no granger causality. ${ }^{*},{ }^{* *}{ }^{* * *}$ means that the null hypothesis is rejected at a $10 \%, 5 \%, 1 \%$ level, otherwise the null hypothesis of no causality is not rejected.

Table 15 - Rwandan and Peruvian convergence test results

\begin{tabular}{llllll}
\hline Variables convergence tests & GDPcs & GCFCS & Agrcs & IntTcs & Mancs \\
\hline Treatments & $(2,116)$ & $(2,116)$ & $(2,116)$ & $(2,116)$ & $(2,116)$ \\
Df & $(1,114)$ & $(1,114)$ & $(1,114)$ & $(1,114)$ & $(1,114)$ \\
F value & 763 & 166.8 & 335.3 & 37.04 & 1473 \\
P value & $2 \mathrm{e}-16^{* * *}$ & $2 \mathrm{e}-16^{* * *}$ & $2 \mathrm{e}-16 * * *$ & $1.59 \mathrm{e}-08^{* * *}$ & $2 \mathrm{e}-16^{* * *}$ \\
\hline
\end{tabular}

Note: ANOVA test statistics economic variables means are not the same (not converging) is the null hypothesis. ${ }^{*}{ }^{* *},{ }^{* *}$ implies the rejection of the null hypothesis at a 10\%, 5\%, 1\% level, otherwise the null hypothesis is not rejected.

\section{DISCUSSION OF RESULTS}

This research collects Rwandan and Peruvian annual time series data from 1960 to 2017 on Per capita GDP with some of its vital explanatory variables, from the World Bank dataset 2018. The summary statistics of variables and Per capita GDP trends increased across time are explained in Table 2.

Tourism and gross capital formation for both countries exhibited a more significant coefficient of variation (CV) greater than $50 \%$ for both countries, as in Table 2 . The overall Per capita GDP average growth rates for both two countries from 1960 to 2017 were almost the same, with only an insignificant difference of $0.006 \%$ as it was $1.467 \%$ and $1.461 \%$ for Rwanda and Peru, respectively.

After collinearity issues avoidance among the explanatory variables, and all Statistical tests elaborated, using both $\mathrm{R}^{2}$-adjusted and Jarque Bera tests results as presented in Table 10. 
The estimated values support a generalized Broadwell model equation with linear and quadratic terms, with an appropriate model Equation (10) employed to analyze the long-run correlation status among variables.

With the Specified lag length, the next step presented by Table 11 was to test if the cointegration among variables exists or not using the Johansen test results. At a 0.05 level of significance, the no cointegrating equation null hypothesis is rejected by the trace and eigenvalue tests, indicating at least one cointegration equation existence for each country.

According to normalized cointegrating coefficients as shown by Table 12, countries' long-run correlation equations are:

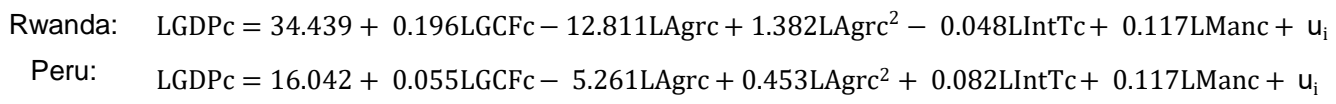

As the above equations on Rwandan situation; the estimated normalized cointegrating vector with respect to the explanatory variables are: $(1,0.196),(1,0.117),(1,-0.048)$, $(1,-12.811)$ and $(1,1.382)$, for LGCFc, LManc, LIntTc, LAgrc, and LAgrc^2 explanatory variables respectively. It implies that keeping other terms constant sequentially. For monotonic variables, a 1\% increment in the Per capita Gross capital formation (GCFC), and Per capita Manufacturing, value added (Manc), result to a raise in GDP per capita (GDPc) of $0.196 \%$, and $0.117 \%$ in the long run sequentially. Moreover, a $1 \%$ increment in Per capita International tourism, expenditures (IntTc) will lead to a decrease in GDP per capita (GDPc) by $0.048 \%$ in the long run. For mixed trends, a $1 \%$ raise in Per capita Agriculture, forestry, and fishing, value added (Agrc), led to a decrease of growth in GDP per capita (GDPc) by $12.811 \%$ up to the turning point in 1974. After turning point, an increase in growth of per capita GDP (GDPc) with $1.382 \%$ in the long run. The scenario is also the same for the Peruvian case, with the turning point in 1984 of the mixed trend. The cointegration indicates causality occurrence, at least in one way orientation. Though, it doesn't designate the causality orientation. Thus, for causality direction clarification, the Error Correction Model $(E C M)$ established by the causality tests is conducted. The short-run Chi-square $\left(x^{2}\right)$ test, long-run T-test, and the joint F-test for Equations (4), (5) and (6) are defined in Table 13 and Table 14. For the Rwandan situation at a $5 \%$ significance level, the short-run dynamics for all independent variables insinuate causality to the GDPc. At a $10 \%$ level of significance, the GDPc suggests causality to the Agr. While for the Peruvian situation, the dynamic short-run introduce the one way directional causality from GDPc to its explanatory variables except for the GCFc and INTTC. The ECT coefficient determined is significant statistically in each equation for Rwanda, and Peru accepts some cases demonstrated in the tables. Implying that, whenever the system shock appeared a short-run adaptation (adjustment) on each variable is executed to reestablishment the long-run stability or equilibrium.

The convergence scenario calculated using an analysis of variance calculated in Table 15. The tabulated value for d.f $(1,114)$, at a $5 \%$ level of significance, is 3.9201 . Comparing this value with the calculated $F$ values of both countries, we realize that $763,166.8,335.3$, 37.04 , and 1473 all are $>3.9201$. Hence the null hypothesis that economic variables means are not the same (not converging) is rejected; therefore, there was an economic convergence of Rwanda and Peruvian from 1960 to 2017.

\section{CONCLUSION AND POLICY IMPLICATIONS}

The paper is inspecting on economic growth models, causality, and convergence basing on the relationship between economic variables of Rwanda and Peru, two developing countries with a different status including geographic location during the period of 1960-2017. Cointegration technique, Granger causality test, and analysis of variance tools were applied to explore the causal relation and convergence status among variables.

Generally, an increase in the growth of chosen explanatory variables leads to an increase of income growth in the long run for both countries. These relationships within both countries demonstrate an exceeding positive influence of agriculture output on income 
changes than other variables. A double directional strong Granger causality linking the growing economy with its independent variables indicates that the two variables are mutually defined and concerned at the same moment. Such that raising in independent variables boosts economic growth also vice versa. Three determinants at least described the scenario: scale, technique impacts, and efficiency of explanatory variables. Firstly, the scale impact occurs as explanatory variables rise; this will raise the GDP. Secondly, the explanatory variables improvement depends on elaborated production techniques due to income availability. Finally, for economic growth continuity pursuance, governments need more improved efforts to explanatory variables and equipment, decreasing unnecessary loss during variables generation, transmission and delivery, also the introduction of various kinds of economic improvements. An exceptional case in Rwanda arose where tourism production Per capita increased at the expense of GDPc. It is explained by the fact that for tourism improvement; the country is depriving specific economic generators, which are not yet recovered by the tourism outcome. Rwanda should embrace a binary strategy of increasing tourism investment and maximize its outcome, step up and review some tourism conservation policies to reduce the needless loss for the tourist restoration areas and other tourism costs to avoid hurting economic growth.

Regarding the economic convergence; despite the multiple different situations of each country geographic aspect included, we realize the same general average growth of gross domestic production per capita, the same model explaining the relationship between economic growth of each of these two countries and its explanatory variables, as well as the same means for each of the variables compared in a juxtaposed manner between two countries. The analyses show that these countries have a significant possibility of having the same economic situations. Thus, developing countries are called, not to be too afraid of their different multi situations, including the geographical aspect, and opt for conventional policies emerging their economic situations.

\section{REFERENCES}

1. Alexander Mapfumo. An Econometric Analysis of the Relationship between Agricultural Production and Economic Growth in Zimbabwe. no. 23, 2012, pp. 11-15, doi:10.18551/rjoas.2013-11.02.

2. Bony, Jean Michel. "Solutions Globales Bornées Pour Les Modèles Discrets de l'équationde Boltzmann En Dimension 1 d'espace." Journées Équations Aux Dérivées Partielles, no. 1987, 2018, pp. 1-10,

3. Broadwell, James E. "Shock Structure in a Simple Discrete Velocity Gas." Physics of Fluids, vol. 7, 1964, p. 1243-1247, doi:10.1063/1.1711368.

4. Clarke, Brenton R. The Theory and Application of Analysis of Variance. A JOHN WILEY \& SONS, INC, 2008.

5. Denisard C.O. Alves, Rodrigo De Losso. "Short-Run, Long-Run and Cross Elasticities of Gasoline Demand in Brazil." Energy, vol. 25, 2003, pp. 191-99.

6. Dickey David A., and Fuller Wayne A. "Likelihood Ratio Statistics for Autoregressive Time Series with a Unit Root." Econometrica, vol. 49, no. 4, 1981, pp. 1057-72, doi:10.2307/1912517.

7. Djennas, Mustapha, and Belkacem Ferouani. "Growth and Income Convergence in Africa." Journal of Economics and Development Studies, vol. 2, no. 4, 2014, pp. 63-76, doi:10.15640/jeds.v2n4a5.

8. Dramani, Latif A. G. Convergence and Economic Integration in Africa: The Case of the Franc Zone Countries. no. August, the African Economic Research Consortium, 2010.

9. Engle, Robert F., et al. "Co-Integration and Error Correction : Representation, Estimation, and Testing." Econometrica, vol. 55, no. 2, 1987, pp. 251-76, https://www.jstor.org/stable/1913236.

10. Gómez, Roman Salmerón, et al. "Collinearity Diagnostic Applied in Ridge Estimation through the Variance Inflation Factor." Journal of Applied Statistics, vol. 43, no. 10, 2016, pp. 1831-49, doi:10.1080/02664763.2015.1120712. 
11. INEI. Produccion Nacional Oct 2019. 2019.

12. Jarque, BERA. Efficient Tests for Normality, Homoscedasticity and Serial Independence of Regression Residuals. 1980, pp. 255-59.

13. Khan, Faiza A. "Economic Convergence in the African Continent: Closing the Gap." South African Journal of Economics, vol. 82, no. 3, 2014, pp. 354-70, doi:10.1111/saje.12032.

14. Kwiatkowski, Denis, and Peter C. B. Phillips. "Testing the Null Hypothesis of Stationarity against the Alternative of a Unit Root How Sure Are We That Economic Time Series Have a Unit Root ?*." Journal of Econometrics, vol. 54, 1992, pp. 159-78.

15. NISR. Formal External Trade Report in Goods. no. April, 2018.

16. Oxley, Les, and David Greasley. "Vector Autoregression, Cointegration and Causality: Testing for Causes of the British Industrial Revolution." Applied Economics, vol. 30, no. 10, 1998, pp. 1387-97, doi:10.1080/000368498325002.

17. Phillips, Peter C. B. "Testing for a Unit Root in Time Series Regression." Biometrika, vol. 75, no. 2, 1988, pp. 335-46.

18. SOLOW, Robert M. "A Contribution to the Theory of Economic Growth Author ( $\mathrm{s}$ ): Robert M. Solow Source." The Quartely Journal of Economics, vol. 70, no. 1, 2009, pp. 65-94, http://www.jstor.org/stable/1884513.

19. Søren Johansen, Katarina Juselius. "Cointegration and Error Correction: Representation, Estimation, and Testing." Oxford Bulletin of Economics and Statistics, vol. 52, no. 2, 1990, pp. 169-210.

20. Yamazaki, Mitsuru. "Generalized Broadwell Models for the Discrete Boltzman Equation with Linear and Quadratic Terms." Mathematical Methods in the Applied Sciences, vol. 23, no. 1, 2000, pp. 63-69, doi:10.1002/(SICI)1099-1476(20000110)23:1<63::AIDMMA103>3.0.CO;2-0. 